\title{
Dramatic Improvement of Diabetes Mellitus Following the Treatment of Coexisting Acromegaly and Cushing's Syndrome
}

\author{
Soo Kyoung Kim ${ }^{1,2}$, Bo Ra Kim ${ }^{1}$, Kyongyoung Kim ${ }^{1}$, Sungsu Kim ${ }^{1}$, \\ Jung Hwa Jung ${ }^{1,2}$, Jong Ryeal Hahm ${ }^{1,2}$ and Jaehoon Jung ${ }^{1,2}$
}

\begin{abstract}
Endocrine diseases are frequently accompanied by diabetes mellitus and treatment of an underlying endocrine disease often improves glucose control. The co-occurrence of acromegaly and Cushing's syndrome is extremely rare. We herein describe a patient who showed a dramatic improvement in glucose control following treatment for co-existing acromegaly and Cushing's syndrome. An adrenal mass was incidentally discovered during a routine evaluation of a 56-year-old woman who was subsequently diagnosed with acromegaly and a unilateral cortisol-producing adrenal adenoma. Her blood glucose was poorly controlled despite receiving high-dose insulin therapy. After undergoing adrenalectomy for Cushing's syndrome, her insulin dosage was decreased by almost 50\%. The insulin treatment was discontinued following the treatment of acromegaly.
\end{abstract}

Key words: acromegaly, Cushing's syndrome, diabetes mellitus

(Intern Med 54: 2471-2474, 2015)

(DOI: 10.2169/internalmedicine.54.3302)

\section{Introduction}

Endocrine diseases, including pituitary and adrenal diseases, are frequently accompanied by the secondary occurrence of diabetes mellitus (1-3). Growth hormone (GH) and glucocorticoids can block the actions of insulin, resulting in diabetes mellitus $(1,4)$. There have been several studies regarding the mechanism of increased insulin resistance in acromegaly patients. Hansen et al. reported that $\mathrm{GH}$ may trigger insulin resistance by altering the function at the postbinding stage, and in vitro observations revealed that $\mathrm{GH}$ decreases insulin binding at high concentrations of insulin $(5,6)$.

Both acromegaly and Cushing's syndrome are rare diseases, making the likelihood of both occurring in one individual extremely low. To the best of our knowledge, only 5 such cases have been reported in the literature (7-11). We herein describe a 56-year-old woman with both acromegaly and a unilateral cortisol-producing adrenal adenoma who showed a dramatic improvement in glucose control following the treatment of her acromegaly and Cushing's syndrome.

\section{Case Report}

A 56-year-old woman was admitted to the endocrinology department of our hospital for the evaluation of uncontrolled diabetes mellitus and an incidentally discovered adrenal mass. The patient had been diagnosed with diabetes mellitus five years prior. The patient denied any family history of diabetes mellitus or multiple endocrine neoplasia (MEN).

On the physical examination, the patient presented with the typical features of acromegaly and Cushing's syndrome (central obesity, moon-like face with an enlarged nose, plethora, and a sonorous deep voice). However, she had never undergone any examination specifically for acromegaly or Cushing's syndrome. After admission, the patient was diagnosed with Cushing's syndrome based on the typical clinical characteristics and laboratory findings. Her

${ }^{1}$ Department of Internal Medicine, Gyeongsang National University School of Medicine, South Korea and ${ }^{2}$ Gyeongsang Institute of Health Science, Gyeongsang National University School of Medicine, South Korea

Received for publication May 16, 2014; Accepted for publication December 21, 2014

Correspondence to Dr. Jaehoon Jung, taesikjung@gmail.com 
(A)

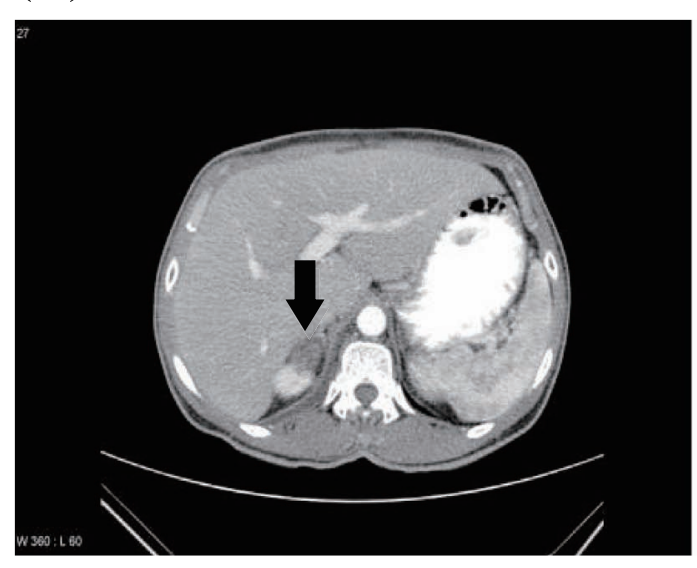

(B)

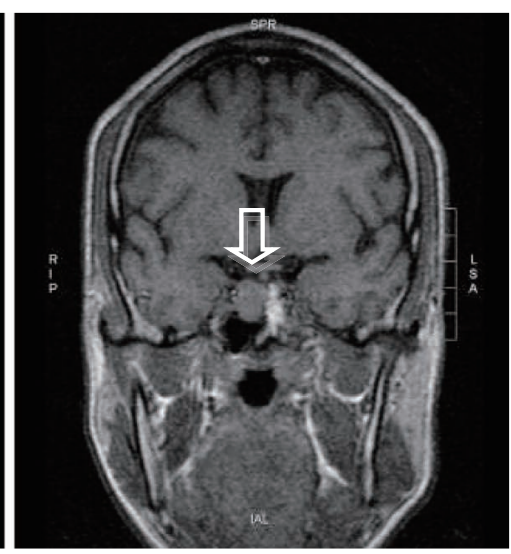

Figure 1. (A) Adrenal enhanced computed tomography shows a $4 \mathrm{~cm}$-sized right adrenal tumor (arrow). (B) The coronal image of a gadolinium-enhanced magnetic resonance image of the pituitary gland shows a $1.5 \mathrm{~cm}$-sized pituitary adenoma (arrow).

plasma adrenocorticotropic hormone (ACTH) concentration was $4.28 \mathrm{pg} / \mathrm{mL}$ (reference range: $5-60 \mathrm{pg} / \mathrm{mL}$ ), serum cortisol level was $18.28 \mathrm{~g} / \mathrm{dL}$, and her 24-hour urinary excretion of cortisol was 1,764 $\mu \mathrm{g}$ /day (reference range: 55-286 $\mu \mathrm{g}$ / day). In the 48-hour low-dose suppression test, the patient's plasma cortisol failed to decrease to less than $2 \mu \mathrm{g} / \mathrm{dL}$ (the serum cortisol level was $15.82 \mu \mathrm{g} / \mathrm{dL}$ after dexemethasone suppression). Adrenal enhanced computed tomography showed a $4 \mathrm{~cm}$-sized adenoma in the right adrenal gland (Fig. 1A). The pituitary hormone tests revealed high baseline concentrations of $\mathrm{GH}(54.25 \mathrm{ng} / \mathrm{mL})$ and insulin-like growth factor (IGF-1; $1,256.2 \mathrm{ng} / \mathrm{mL}$ ). The other hormone results showed an elevated prolactin level $(82.13 \mathrm{ng} / \mathrm{mL})$, a decreased level of thyroid stimulating hormone (TSH; 0.04 $\mathrm{mIU} / \mathrm{L}$ ), a normal level of free thyroxine on the lower end of the range $(0.94 \mathrm{ng} / \mathrm{dL})$ and decreased levels of luteinizing hormone $(\mathrm{LH} ; 0.10 \mathrm{mIU} / \mathrm{mL})$, follicle stimulating hormone (FSH; $0.43 \mathrm{mIU} / \mathrm{mL})$, and estradiol $(5.0 \mathrm{pg} / \mathrm{mL})$. A $75 \mathrm{~g}$ glucose load did not reduce the $\mathrm{GH}$ concentration to $\leq 1 \mu \mathrm{g} /$ L. Brain magnetic resonance imaging (MRI) showed a 1.5 cm-sized pituitary tumor (Fig. 1B).

Thyroid sonography showed a thyroid nodule, which was shown to be benign following fine-needle aspiration cytology. At admission, the patient was receiving multiple-dose insulin injection therapy using the basal-bolus regimen (120 units of insulin glargine +32 units of insulin glulisine three times a day $+1,000 \mathrm{mg}$ metformin) for glucose control. However, her fasting blood glucose concentration was never lower than $200 \mathrm{mg} / \mathrm{dL}$.

The right adrenal tumor was resected in February 2008. Four weeks later, her blood glucose concentration improved, and we reduced her total insulin dosage from 216 to 130 units a day. After adrenalectomy, the hormone results indicated an elevated prolactin $(129.7 \mathrm{ng} / \mathrm{mL})$, a normal level of $\mathrm{TSH}$ on the lower end of the range $(0.80 \mathrm{mIU} / \mathrm{L})$ with a normal level of free thyroxine $(1.15 \mathrm{ng} / \mathrm{dL})$, and decreased levels of LH $(0.10 \mathrm{mIU} / \mathrm{mL})$ and FSH $(0.89 \mathrm{mIU} / \mathrm{mL})$ with a low level of estradiol $(5.0 \mathrm{pg} / \mathrm{mL})$. The ACTH level was $29.42 \mathrm{pg} / \mathrm{mL}$, and the cortisol level was $6.71 \mu \mathrm{g} / \mathrm{dL}, 15.46$ $\mu \mathrm{g} / \mathrm{dL}$, and $16.42 \mu \mathrm{g} / \mathrm{dL}$ at 0,30 , and $60 \mathrm{~min}$, respectively, after the ACTH stimulation following right adrenalectomy. The patient was placed on steroid replacement therapy (prednisolone, 2.5-5 mg per day) for 5 months after adrenalectomy. The steroid replacement therapy was stopped after normalization of the cortisol response.

The surgical removal of the pituitary macroadenoma was delayed by the patient for personal reasons. Five years later, at 63 years of age, the patient underwent selective transsphenoidal removal of the pituitary adenoma. After removal of the pituitary macroadenoma, the hormone tests revealed a low prolactin level $(1.68 \mathrm{ng} / \mathrm{mL})$, a normal level of $\mathrm{TSH}$ in the lower end of the range $(0.42 \mathrm{mIU} / \mathrm{L})$, a normal level of free thyroxine $(1.52 \mathrm{ng} / \mathrm{dL})$, and low levels of $\mathrm{LH}$ (2.29 IU/mL), FSH (12.29 mIU/mL), and estradiol (7.4 pg/ $\mathrm{mL})$. Over the next month, her total insulin dose was markedly reduced from 74 to 30 units per day (30 units of insulin glargine $+1,000 \mathrm{mg}$ metformin). The insulin therapy was subsequently discontinued due to repeated episodes of hypoglycemia, and the patient took only metformin $(1,000$ mg/day) (Fig. 2). A 75 g glucose load suppressed her GH concentration to $<1 \mu \mathrm{g} / \mathrm{L}$, thus indicating that her acromegaly had been cured.

\section{Discussion}

In the present study, the patient had two interesting characteristics. The first was the co-occurrence of acromegaly and Cushing's syndrome. This unusual presentation may be due to an endocrine syndrome, such as MEN or Carney's complex, as demonstrated in previous studies. Alzahrani et al. (11) described Cushing's syndrome as the initial manifestation of MEN type 1 (MEN 1). Their case, contrary to ours, showed the evidence of hyperparathyroidism (12). Our patient had normocalcemia, normal parathyroid and pancreas 


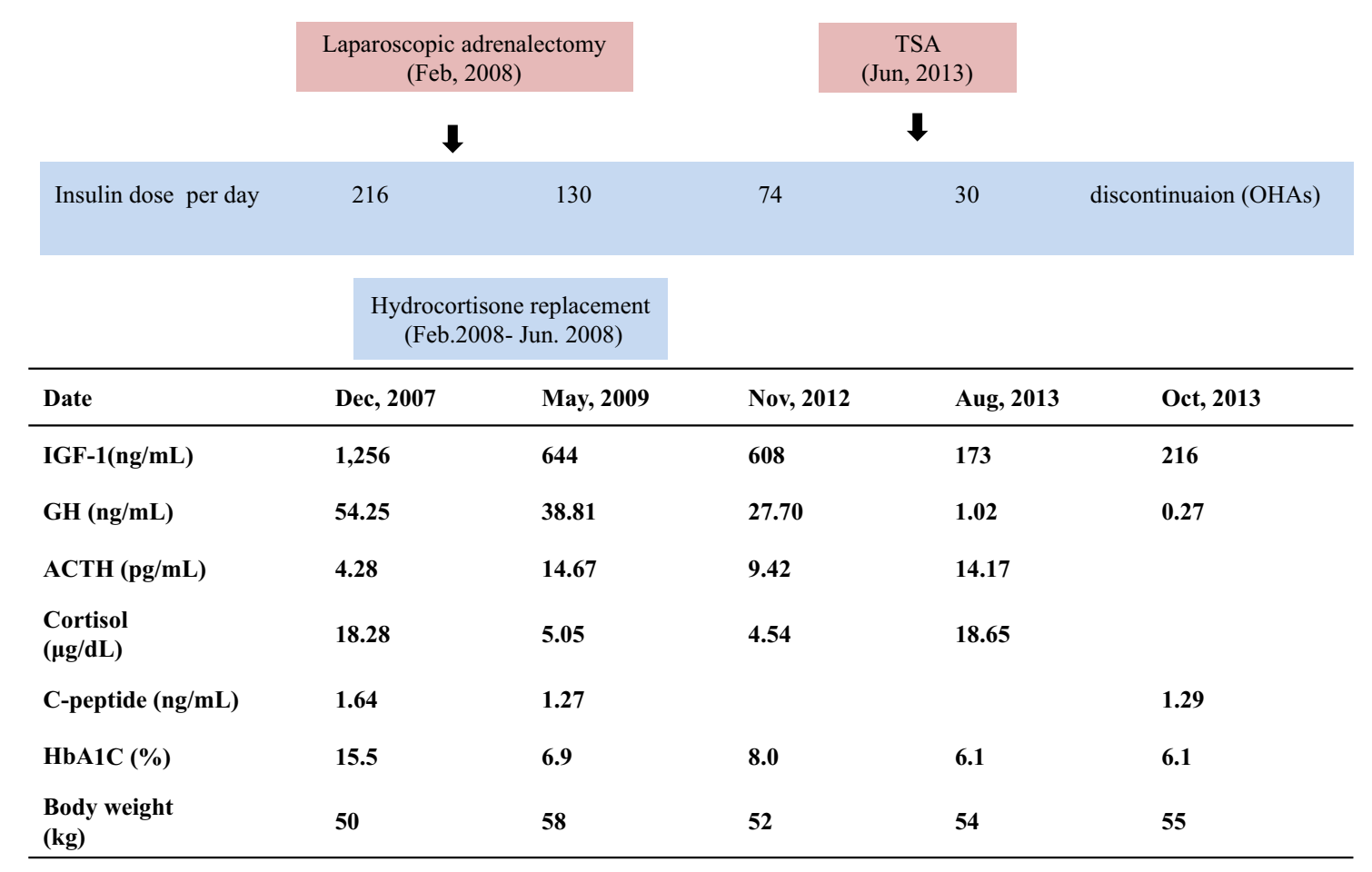

Figure 2. The patient's clinical course and biochemical laboratory results after undergoing laparoscopic adrenalectomy for a right adrenal adenoma and transsphenoidal adenomectomy for a pituitary adenoma. TSA: transsphenoidal adenomectomy

features on the computed tomography images, and no family history of endocrine diseases, making MEN 1 unlikely. The simultaneous occurrence of acromegaly and Cushing's syndrome in a single patient may also be due to Carney's complex (13), which is characterized by primary pigmented nodular adrenocortical disease, thyroid nodules, myxoma, and acromegaly. Cushing's syndrome in our patient was not due to a primary pigmented nodular adrenocortical disease. Moreover, our patient did not have any other lesions typically associated with Carney's complex, such as myxoma. It is known that the treatment with glucocorticoids over physiological levels inhibits GH secretion in patients with acromegaly (14). However, our case showed a decrease in both the GH and IGF-1 levels after adrenalectomy, similar to a previous report by Uchida et al. (8). The GH and IGF-1 levels did not normalize and the size of pituitary mass remained unchanged in the present case. Though the precise mechanism of this phenomenon cannot be explained, it implies that glucocorticoid secretion is associated with $\mathrm{GH}$ secretion in acromegaly patients.

Acromegaly has been under-recognized, and the clinical recognition of acromegaly has not significantly improved over the last 25 years (15). The clinical suspicion is also important in Cushing's syndrome due to its low specificity of symptoms (16). The diagnosis of acromegaly and Cushing's syndrome in our patient was delayed, and the tests for endocrine diseases were initiated to evaluate an incidentally discovered adrenal adenoma. Since our patient had mixed features of acromegaly and Cushing's syndrome, it was difficult to identify specific endocrine diseases.
The second interesting characteristic of our patient was that our patient showed dramatic improvements in her glucose control state and no longer required insulin treatment after the resection of the cortisol-producing adrenal adenoma and the subsequent surgery for acromegaly. The relationship between insulin resistance and diabetic status were previously described in two of the five patients with acromegaly and Cushing's syndrome $(7,10)$. In one patient, adrenalectomy and pituitary surgery improved the patient's insulin resistance and glucose control state (10). That patient, however, did not demonstrate marked alterations in the treatment of diabetes, such as the discontinuation of insulin or a dramatic improvement of glucose control. The second patient was not diabetic before left adrenalectomy (7). Reports on the other three patients with acromegaly and Cushing's syndrome did not mention the glucose control status $(8,9,11)$.

The findings in our patient clearly show the deleterious effects of excess $\mathrm{GH}$ and cortisol on glucose metabolism and insulin resistance. Early clinical recognition of acromegaly and Cushing's syndrome is important in the treatment of these rare endocrine diseases in patients with poorly controlled diabetes despite being on high-dose insulin.

The authors state that they have no Conflict of Interest (COI).

\section{References}

1. Resmini E, Minuto F, Colao A, et al. Secondary diabetes associated with principal endocrinopathies: the impact of new treatment modalities. Acta Diabetol 46: 85-95, 2009. 
2. Terzolo M, Reimondo G, Chiodini I, et al. Screening of Cushing's syndrome in outpatients with type 2 diabetes: results of a prospective multicentric study in Italy. J Clin Endocrinol Metab 97: 3467$3475,2012$.

3. Fieffe S, Morange I, Petrossians P, et al. Diabetes in acromegaly, prevalence, risk factors, and evolution: data from the French Acromegaly Registry. Eur J Endocrinol 164: 877-884, 2011.

4. Kim SK, Suh S, Lee JI, et al. The ability of $\beta$-cells to compensate for insulin resistance is restored with a reduction in excess growth hormone in Korean acromegalic patients. J Korean Med Sci 27: 177-183, 2012.

5. Hansen I, Tsalikian E, Beaufrere B, et al. Insulin resistance in acromegaly: defects in both hepatic and extrahepatic insulin action. Am J Physiol 250: 269-273, 1986.

6. Muggeo M, Bar RS, Roth J, et al. The insulin resistance of Acromegaly: evidence for two alterations in the insulin receptor on circulating monocytes. J Clin Endocrinol Metab 48: 17-25, 1979.

7. Ogo A, Matoba Y, Matsuda Y, et al. A decrease in the dose of pegvisomant was needed for the treatment of acromegaly after adrenalectomy in a patient with coexisting preclinical Cushing's syndrome. Intern Med 50: 1987-1991, 2011.

8. Uchida D, Tatsuno I, Nakamura S, et al. Glucocorticoiddependency on GH secretion and tumor growth in a GHproducing pituitary adenoma with Cushing's syndrome. Endocr J 47: 69-71, 2000 .

9. Watanobe H, Kudo K, Okushima T, et al. Coexisting acromegaly and a unilateral cortisolproducing adrenal adenoma: a possible variant of multiple endocrine neoplasia type I. J Endocrinol Invest 15: 297-301, 1992.

10. Nasushita R, Watanobe $H$, Goto $T$, et al. A case of acromegaly accompanied by adrenal preclinical Cushing's syndrome. Endocr J 46: 133-137, 1999.

11. Alzahrani AS, Al-Khaldi N, Shi Y, et al. Diagnosis by serendipity: Cushing syndrome attributable to cortisol-producing adrenal adenoma as the initial manifestation of multiple endocrine neoplasia type 1 due to a rare splicing site MEN1 gene mutation. Endocr Pract 14: 595-602, 2008.

12. Thakker RV, Newey PJ, Walls GV, et al. Clinical practice guidelines for multiple endocrine neoplasia type 1 (MEN1). J Clin Endocrinol Metab 97: 2990-3011, 2012.

13. Daly AF, Tichomirowa MA, Beckers A. The epidemiology and genetics of pituitary adenomas. Best Pract Res Clin Endocrinol Metab 23: 543-554, 2009.

14. Nakagawa K, Akikawa K, Matsubara M, Kubo M. Effect of dexamethasone on growth hormone $(\mathrm{GH})$ response to growth hormone releasing hormone in acromegaly. J Clin Endocrinol Metab 60: 306-310, 1985.

15. Reid TJ, Post KD, Bruce JN, et al. Features at diagnosis of 324 patients with acromegaly did not change from 1981 to 2006: acromegaly remains under-recognized and under-diagnosed. Clin Endocrinol 72: 203-208, 2010.

16. Nieman LK, Biller BM, Findling JW, et al. The diagnosis of Cushing's syndrome: an endocrine society clinical practice guideline. J Clin Endocrinol Metab 93: 1526-1540, 2008.

(C) 2015 The Japanese Society of Internal Medicine http://www.naika.or.jp/imonline/index.html 